\title{
DISCURSOS DE PACIFICAÇÃO E A DIVISÃO DE SENTIDOS E SUJEITOS
}

\section{GRECIELY CRISTINA DA COSTA ${ }^{1}$}

\author{
Programa de Pós-Graduação em Ciências da Linguagem \\ Faculdade de Filosofia, Ciências e Letras Eugênio Pacelli \\ Universidade do Vale do Sapucaí \\ Av. Pref. Tuany Toledo, 470 - 37550-000 - Pouso Alegre-MG - Brasil \\ greciely@gmail.com
}

\begin{abstract}
Resumo. Definida no dicionário de língua portuguesa como ação ou efeito de pacificar, tornar pacífico, como ação que consiste no restabelecimento da paz, a palavra pacificação, ao longo da história, tem dado nome a diferentes modos de regulação social. Interessa-me compreender, da perspectiva da Análise de Discurso, como então tem significado o discurso de pacificação na produção de efeitos de sentido em face do processo sócio-históricoideológico movido pela política de segurança pública do Rio de Janeiro. Para tanto, analiso diferentes discursos sobre a Unidade de Polícia Pacificadora (UPP), nos quais um nó de sentidos é constituído a partir de um processo discursivo em que tanto os sentidos de guerra quanto os sentidos de paz convivem neste nó, explicitando a contradição em jogo.
\end{abstract}

Palavras-chave: Análise de Discurso; pacificação indígena; UPP; regulação social; Estado.

\begin{abstract}
Defined in the dictionary of Portuguese language as action or effect to pacify, make pacific, as action that consists of restoration of peace, the word pacification throughout history has given name to different means of social regulation. I understand, from the perspective of the Discourse Analysis, how then the discourse of pacification has signified within the production of effects of meaning regarding the socio-historical and ideological process moved by public security policy of Rio de Janeiro. Therefore, I analyze different discourses about Unidade de Polícia Pacificadora (UPP), in which a node of senses is constituted from a discursive process in which both senses of war and peace coexist in this node, explaining the contradiction functioning in it.
\end{abstract}

Keywords: Discourse Analysis; indian pacification; UPP; social regulation; state.

A sociedade sempre encontrou formas de categorizações "legitimas" para poder exercer seu poder de exclusão.

ORLANDI, 1990, p. 72).

\footnotetext{
${ }^{1}$ Doutora em Linguística (Unicamp). Docente no Programa de Pós-Graduação em Ciências da Linguagem da Universidade do Vale do Sapucaí.
} 
Assim, a luta ideológica não tem nada a ver com os chamados mal entendidos semânticos que provocam problemas que desapareciam à luz da formulação de uma semântica universal. No terreno da linguagem, a luta de classes ideológica é uma luta pelo sentido das palavras, expressões e enunciados, uma luta vital por cada uma das duas classes sociais opostas que têm se confrontado ao longo da história.

PÊCHEUX, [1977] 2011, p. 273.

\section{Introdução}

Proponho discutir e analisar, neste artigo, a partir da temática da regulação social e suas formas coercitivas, discursos que têm em seu cerne a palavra pacificação produzindo diferentes efeitos de sentido. Discursos que, atravessados por outros, fazem força nas práticas, projetos e ações de regulação das relações sociais por meio da instalação de políticas públicas, ditas de segurança, que muitas vezes funcionam pela repressão policial. De certo modo, busco explicitar o elo entre política, instituição e segurança em meio a relações de força e poder que provocam a divisão de sentidos e sujeitos na sociedade.

Sendo assim, parto do princípio de que discutir a relação entre linguagem e sociedade demanda uma compreensão que considere a articulação do papel da linguagem com a história e com a ideologia. Filiada à Análise de Discurso, tenho investido nessa relação, a partir do estudo dos sentidos das palavras, articulando linguagem e ideologia em face da história (e) das relações sociais. Nesta direção, meu estudo é orientado, sobretudo, pela afirmação de Pêcheux (2011) que explica que, no terreno da linguagem, a luta de classes, em confronto ao longo da história, é uma luta pelo sentido das palavras. É me situando nessa afirmação que almejo então dar visibilidade aos sentidos da palavra pacificação em processos discursivos diferentes, explicitando como se constituem e significam certas relações sociais.

Para isso, retomo o significado dicionarizado de pacificação, os sentidos em jogo nos séculos XVI e XIX em relação aos índios no Brasil dessa época, e chego ao discurso da pacificação no Rio de Janeiro nos dias atuais.

\section{A palavra pacificação e o processo de pacificação indígena}

Como se pode ver na definição disposta a seguir (Imagem 1), a palavra pacificação refere-se diretamente à paz e, em relação aos seus sinônimos, vê-se que pacificação mantém sinonimicamente ligação com reconciliação e com ação de aquietar à medida que apaziguamento e aquietação aparecem aí. No entanto, definida no dicionário eletrônico de língua portuguesa ${ }^{2}$ como ação ou efeito de pacificar, tornar pacífico, como ação que consiste no restabelecimento da paz, a palavra pacificação ao longo da história tem dado nome a diferentes ações e modos de regulação social.

\footnotetext{
${ }^{2}$ Definição de pacificação disponível em <http://www.dicio.com.br/pacificacao/>; acesso em abril de 2015.
} 


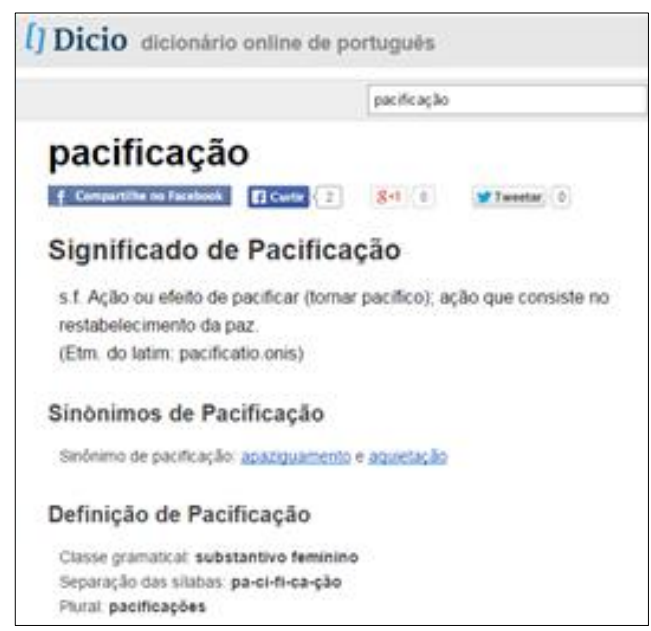

Imagem 1. Dicionário online de Português.

Da perspectiva teórico-analítica da Análise de Discurso, busco compreender como, então, tem significado o discurso de pacificação, que é mobilizado por essa palavra, que se define na relação com paz, no dicionário, mas que tem dado nome a ações e projetos de regulação da sociedade. Interessa-me, portanto, considerando que, de acordo com Orlandi (1999, p. 20), as "palavras simples do nosso cotidiano já chegam até nós carregadas de sentidos que não sabemos como se constituíram e que, no entanto, significam em nós e para nós", como se dá o processo discursivo, cuja significação é desencadeada por uma palavra que faz vir à tona muitos (outros) sentidos.

No Brasil, em relação aos indígenas, no século XVI, "em prol” da conquista de novos territórios, expropriação das terras ocupadas pelos índios e controle das populações indígenas por missionários, Pacheco de Oliveira mostra que a pacificação se configura como um dos princípios de colonização portuguesa de caráter militar na América. Segundo o autor, tratava-se "de promover uma guerra de conquista contra as "nações indígenas', submetendo as populações e as autoridades autóctones ao exclusivo comando de El Rey, transformando as suas terras efetivamente em território português" (PACHECO DE OLIVEIRA, 2014, p. 129-130), cujas coordenadas apresentavam-se em regimentos advindos de Portugal.

A partir da referência ao regimento dado a Tomé de Souza, primeiro governadorgeral do Brasil, em 1548, Pacheco de Oliveira (idem) assinala que a legitimidade da pacificação era balizada, neste documento, pela instituição jurídica denominada "guerra justa" que, segundo o autor, baseava-se nos mesmos procedimentos utilizados contra os muçulmanos no século XIII. No regimento há a recomendação de atrair os índios, fazer guerra aos que se mostrassem inimigos, destruir aldeias, matar, cativar enquanto se negociasse a paz, conforme os seguintes trechos do texto: "atraí-los à paz para a propagação da fé, aumento da povoação e do comércio"; "que se fizesse guerra aos que se mostrassem inimigos [...] destruindo-lhes as aldeias e povoações matando e cativando [...] e fazendo executar nas próprias aldeias alguns Chefes que pudesse aprisionar enquanto negociasse as pazes" 3 .

3 Trechos do Regimento de 1548 enviado a Tomé de Souza. Disponível em <http://www.overmundo.com.br/overblog/a-escravidao-do-indio-brasileiro-i-1. Acesso em: 10 de maio de 2015>; acesso em abril de 2016. 
Descritos como ferozes, rebeldes, índios bravos, persistentes ao paganismo, influenciados por demônios, os Tupinambás reagiam à conversão religiosa e à autoridade portuguesa. Como consequência, muitas aldeias foram destruídas. Além dos Tupinambás, também, muitos outros índios foram executados e os sobreviventes, ditos pacificados, foram submetidos ao controle de território e domínio português. Essa era a prática denominada pacificação, no século XVI, que dá nome a um dos princípios de colonização de caráter militar.

Pacificação instituída pela guerra justa é a discursividade que aponta para a produção da violência institucionalizada e, portanto, legitimada. Para um nó de sentidos de guerra, que é dita justa, de pacificação que, portanto, não significa paz, e de violência, que é o seu resultado. Aponta também para as relações de força entre o colonizador e o colonizado, cuja imagem do índio, pensando as formações imaginárias, é a de inimigo.

Para a Análise de Discurso, de acordo com Pêcheux ([1975] 1988, p. 161; grifos do autor):
uma palavra, uma expressão, ou uma proposição não tem um sentido que lhe seria "próprio", vinculado a sua literalidade. Ao contrário, seu sentido se constitui em cada formação discursiva, nas relações que tais palavras, expressões ou proposições mantêm com outras palavras, expressões ou proposições da mesma formação discursiva.

Pêcheux ([1975] 1988) explica que o sentido é determinado pelas posições ideológicas que, por sua vez, se constituem na relação com a exterioridade, em uma dada conjuntura sócio-histórica. O sentido de uma palavra é assim determinado pela relação que mantém com outras palavras, com outras posições, em diferentes formações discursivas justamente porque as formações discursivas representam no discurso as formações ideológicas. Com isso, o autor assinala que a formação discursiva (FD) é o lugar mais ou menos provisório do sentido. Ele se constitui nesse lugar através de relações de metáfora, pois como assevera Pêcheux ([1975] 1988, p. 263), "o sentido é sempre uma palavra, uma expressão ou uma proposição por uma outra [...] o sentido existe nas relações de metáfora (realizadas em efeitos de substituição, paráfrases, formações de sinônimos)", isto é, no processo discursivo.

Considerando a afirmação do autor, pode-se observar que o discurso da pacificação, na conjuntura sócio-histórica-ideológica da colonização, dá a ver que o sentido de pacificação está na relação com guerra, significada como justa é o que explicita esse adjetivo. No entanto, é com violência que se institui. Seu objetivo não é a paz, mas a expansão territorial e econômica dos colonizadores no Brasil. Eu perguntaria então que guerra é essa? Ela é justa para quem? São perguntas que permitem desnaturalizar o sentido tanto de pacificação quanto de guerra justa e, ao mesmo tempo, observar o processo social no qual a pacificação está inserida.

Já no final do século XIX, a história oficial apresenta a pacificação de índios como sendo uma forma de ação humanitária, cujo objetivo era proteger as tribos do impacto do suposto primeiro contato com os não-índios e risco de extermínio.

Empreendida pelo Serviço de Proteção aos Índios (SPI), instituição legitimadora da pacificação, neste período, que é marcado pela política indigenista, segundo Pacheco de Oliveira (2014, p. 137), a pacificação "passou a descrever um processo dito 
humanitário exercido pelo Estado no sentido de proteger uma população altamente vulnerável e desfavorecida, agora a ser contatada sem o exercício da violência".

Observa-se que de temíveis, os índios passam a ser denominados vulneráveis e desfavorecidos. No entanto, o que não é dito sobre a pacificação, nesta conjuntura, é que ela foi fundamental para isolar populações indígenas em pequenas porções de terras em detrimento da liberação de grandes territórios para serem apropriados por interesses privados (PACHECO DE OLIVEIRA, 2014).

O processo de pacificação, então, encabeçado pelo Estado e gerido pelo SPI, neste período, ao contrário de impor aos indígenas a violência do trabalho forçado e da imposição do cristianismo, dizia garantir o direito de preservação dos usos e costumes indígenas, mas com uma condição, a de que os índios vivessem, conforme explica Pacheco de Oliveira, "sob a proteção dos agentes do Estado brasileiro, no interior de terras de domínio público, que lhes eram reservadas em usufruto exclusivo enquanto sobrevivessem como culturas distintas da sociedade nacional" (PACHECO DE OLIVEIRA, 2014, p. 129).

Nota-se aí a relação da palavra pacificação com proteção. Essa relação me permite indagar pela proteção de quem ou do quê? Dita dos índios, mas em função da apropriação de suas terras. Mais uma vez o sentido de pacificação está longe de se referir à paz.

No momento de colonização do Brasil, os interesses da pacificação para Portugal diziam respeito à apropriação de terras. No Brasil do século XIX, refere-se aos interesses do Estado brasileiro na demarcação de seu território. Mais uma vez a expansão territorial e econômica se presentificam no processo de pacificação como sendo seu real propósito.

O "Jornal do Comércio", de 1968, apresenta a notícia "Expedição 'tentará' pacificação de índios que impedem estrada", que situa a pacificação dos índios, agora dos Waimiris-Atroaris, no momento de construção da rodovia BR-174, que ligaria Manaus a Caracaraí. A notícia refere-se a uma tentativa de pacificação, pois "tentará" aparece aspado. Já para dar visibilidade ao modo como o objetivo da pacificação é textualizado, apresento, abaixo, três recortes da notícia, cujos grifos são meus.

Recorte 1: Os índios Waimiris e Atroaris, cujas malocas se localizam exatamente na faixa por onde deverá passar a BR-174, são por isso mesmo o grande objetivo desta fase de construção da estrada, estando sua pacificação a justificar a reunião de esforços da Fundação Nacional do Índio, da Prelazia de Roraima do Distrito local do DNER que financiará quase toda a expedição do DER-AM, da Aeronáutica e do GEF.

Recorte 2: A experiência do Padre João Calleri, que há alguns anos vem se dedicando ao contato com os silvicolas foi convocada tendo em vista a ferocidade impar dos Waimiris, que serão os mais temidos da região. A isso se acrescenta uma tradição de ódio e desconfiança formada ao longo dos últimos 300 anos de infelizes contatos com que com eles os brancos tentaram estabelecer.

\footnotetext{
${ }^{4}$ Notícia "Expedição tentará pacificação de índios que impedem estrada", 10/10/1968. Fonte: Jornal do Comércio. Disponível na íntegra $\quad \mathrm{em}$ <http://pib.socioambiental.org/anexos/21833_20120511_113033.pdf.>; acesso em março de 2015.
} 


\section{Recorte 3: Liderada pelo Padre João Calleri a expedição terá oito homens e três mulheres (cuja presença dará aos silvicolas a impressão de um movimento normal de família)...}

Nota-se que há, no recorte 1, uma descontinuidade sintática à medida que se enuncia "Os índios Waimiris e Atroaris" (sujeitos da frase) e na sequência o predicado "são por isso mesmo o grande objetivo desta fase de construção da estrada...", que não diz respeito aos índios, mas dá ênfase à sua pacificação, aos esforços das instituições mencionadas para o "grande objetivo".

A notícia não explica como se dará a pacificação. Por outro lado, como se pode observar no recorte 2, enfatiza a experiência do Padre que a liderará, a presença militar e religiosa na expedição, a ferocidade dos "temíveis" Waimiris-Atroaris.

Também se refere a uma tradição de ódio e desconfiança que seria resultado de contatos infelizes entre índios e brancos. Não se diz quem odeia e desconfia de quem. Ficam elididos os sujeitos, fica elidido um sentido de pacificação; enquanto ódio e desconfiança apresentam-se naturalizados como sendo uma tradição. Desse modo, naturalizam-se também os conflitos e o que deles resultou.

Por último, o jornal deixa a ver, no recorte 3, qual seria a estratégia da expedição de modo a explicitar a formação imaginária do índio como aquele "sensível" à formação familiar por conta da presença de homens e mulheres.

É interessante observar o movimento de sentidos em vestígios deixados no subtítulo da notícia que se textualiza: pacificar para integrar, que permite a formulação das seguintes paráfrases (P1 e P2):

P1: Pacificar os índios para integrar suas terras ao território nacional (do Estado)

P2: Pacificar a população para integrar os índios à sociedade de não-índios

As duas paráfrases produzem dois efeitos de sentido diferentes. A primeira coloca o índio como aquele a ser pacificado em proveito da apropriação de suas terras pelo Estado numa relação com a memória de pacificação indígena do Brasil, tanto em relação à colonização quanto à política indigenista, em que pacificar deriva para dominar. Tratase da memória de dominação de certo modo aí ressoando.

A segunda faz vir à tona a tentativa de preparar a população, que "temeria" a sociedade indígena, para uma suposta aproximação com a sociedade indígena, tendo em vista que, sem terras e com a rodovia, índios e não-índios teriam de conviver mais de perto. Uma possibilidade que vemos não se realizar.

Porém, essas são duas possibilidades de compreender o processo de pacificação, cujos sentidos marcam a divisão da sociedade, o conflito social, suas fronteiras tanto territoriais quanto de significação, da qual fazem parte o Estado e suas instituições. 
Em termos de condições de produção, é importante ressaltar que o governo da época era militar e, em plena ditadura, a política nacional-desenvolvimentista ecoava em nome de ordem, progresso e desenvolvimento, como podemos observar nos dizeres do governador do Amazonas, Danilo Areosa, que, a respeito da pacificação dos Wairimis, afirmou, no jornal "A crítica", a necessidade de o índio "ser transformado em ser humano útil á Pátria"5. E ainda, que os índios ocupavam "as áreas mais ricas de nosso Estado, impedindo a sua exploração, com prejuízos incalculáveis para a receita nacional, impossibilitando a captação de maiores recursos para a prestação de serviços públicos". Na mesma direção, o Governador de Roraima, Fernando Ramos Pereira, anunciou ser "de opinião que uma área rica como essa não pode se dar ao luxo de conservar meia dúzia de tribos indígenas atravancando o seu desenvolvimento"6.

O índio, no discurso desses governantes, é significado como inútil, aquele que atravancava o desenvolvimento, que impedia a exploração de certas áreas e, portanto, a geração de lucro. O resultado desse projeto de pacificação foi um massacre. A população dos Waimiris-Atroaris foi reduzida de cerca de 3000 mil para 1000 índios após intervenção militar maciça, segundo os números oficiais que, possivelmente, são inferiores aos não oficiais.

\section{O conceito de pacificação}

Em Terra à vista, Orlandi (1990) discute o conceito de pacificação a partir da análise do relato de Nimuendaju, etnólogo alemão, sobre a pacificação dos parintintins. A autora mostra que pacificar significa em um dos fragmentos por ela analisados "intervir no espaço físico de forma permanente" (ORLANDI, 1990, p. 76).

Já em um segundo recorte, o conceito intensifica a ideia de intervenção, definindose como "intervenção em outro espaço: o do poder e o da representação política do branco sobre o índio" (ORLANDI, 1990, p. 77).

Orlandi observa que, em ambos os fragmentos analisados, a pacificação tem sempre a "mesma direção: colocar o branco entre o índio e o branco, e, mais radicalmente, colocar o branco entre o índio e o outro índio. Isto é intervir: colocar o branco, com sua forma de governo e poder, mediando o índio com sua própria cultura" (ORLANDI, 1990, p. 77).

Nessas condições de produção do discurso, o sentido de pacificação, enquanto ação de restabelecimento da paz, com o sentido de paz aí como se retomada de um momento anterior, se produzido, em alguma instância, é equívoco. Partindo do pressuposto de que, conforme assevera Orlandi, a língua não é transparente, é sujeita a falhas e ao equívoco, a opacidade da palavra pacificação explicita em seu funcionamento

\footnotetext{
5 Publicado em A Crítica, Manaus, 27 de novembro de 1968. Menção em <http://www.cartacapital.com.br/politica/2000-waimiri-atroari-desaparecidos-na-ditadura>; acesso em março de 2015.

6 Publicado em (Resist. Waimiri-Atroari/Marewa/Itacoatiaria/1983, pg. 6). Menção em <http://www.cartacapital.com.br/politica/2000-waimiri-atroari-desaparecidos-na-ditadura>; acesso em março de 2015.
} 
discursivo, até agora analisado, a complexidade de conflitos sociais que são constituídos, em boa medida, pelas políticas econômicas e de Estado, sobretudo, culminando em guerra e não em paz. Em uma fronteira de sentidos que demarcou o lugar do índio e do branco, instituindo a figura do inimigo. Demarcou, ainda, a intervenção como uma necessidade diante de um "perigo", uma "ameaça".

Em sua pesquisa, Orlandi explicita que o processo de pacificação, no século XIX, produziu um apagamento da cultura indígena, anulando qualquer forma de resistência em detrimento da construção de imaginário de índio como aquele que "deve' submeter-se ao branco, que 'deve' reconhecer a autoridade do branco" (ORLANDI, 1990, p.77).

É importante destacar que o conceito de pacificação aparece em outros momentos históricos com sentidos diferentes. Na Argentina, por exemplo, em 1983, foi promulgada a Lei da Pacificação Nacional, que "declarava prescritos todos os delitos ligados à repressão" (NOVARO; PALERMO, 2007, p. 664) em relação aos dirigentes da ditadura militar. Essa lei impedia as investigações, prisões etc., extinguindo qualquer ação penal relativa aos políticos e militares da ditadura.

$\mathrm{Na}$ lei, dita de pacificação, aparece, como justificativa para extinção das ações penais, a figura do inimigo - terrorista, subversivo -, a partir do modo como, no documento chamado, as práticas de resistência em face da ditadura são chamadas de atividades terroristas ou subversivas, conforme se lê em: "en ocasión o con motivo del desarrollo de acciones dirigidas a prevenir, conjurar o poner fin a las referidas actividades terroristas o subversivas, cualquiera hubiere sido su naturaleza o el bien jurídico lesionado"7.

O conceito de pacificação aqui não é o mesmo da pacificação indígena, e, embora não seja objetivo me deter na análise dessa lei, é possível, ainda que muito preliminarmente, observar que, novamente, a palavra pacificação aparece investida em um nó de significações, intervindo em práticas de regulação da sociedade de maneira a delimitar e a neutralizar certos sentidos em detrimento da construção imaginária da figura do inimigo, de perigo ou ameaça. À medida que dá nome a uma lei que exime aquele a ser condenado, inverte o processo social, histórico e político; mexe na rede de sentidos, nas filiações à memória discursiva.

A pacificação enquanto conceito será mobilizada outras vezes e de diferentes maneiras na relação com as forças militares, como no caso da UPP, que discutimos a seguir.

\section{Unidade de Polícia Pacificadora}

Em 2008, foi implantada, no Rio de Janeiro, a Unidade de Polícia Pacificadora, a UPP, definida como um programa que faz de um projeto de segurança pública, que instala unidades de policiais nas favelas cariocas.

\footnotetext{
7 Ley de Pacificación Nacional. Disponível na íntegra em <http://infoleg.mecon.gov.ar/infolegInternet/anexos/70000-74999/73271/norma.htm>; $\quad$ acesso em setembro de 2015 .
} 
Ao se enunciar pacificação, neste contexto, há uma atualização do sentido de pacificação à medida que se marca um encontro entre a atualidade e a memória, pois a palavra pacificação, neste caso, é enunciada em condições de produção diferentes por sujeitos diferentes. No entanto, como explica Orlandi (1999, p. 43), "as palavras falam com outras palavras. Toda palavra é sempre parte de um discurso. E todo discurso se delineia na relação com outros: dizeres presentes e dizeres que se alojam na memória".

As condições de produção do discurso da-e-sobre a UPP são diferentes das condições de produção discursivas do Brasil Colônia ou do Brasil do século XIX. A pacificação não se refere mais aos índios. Não se trata de pacificar os índios, de pacificação indígena. O processo de pacificação é enunciado atualmente em referência ao Rio de Janeiro, a partir de um espaço específico da cidade, a favela. É a polícia dita pacificadora, a que "restabeleceria" a paz. Quem são os pacificados? O que significa pacificação na atual conjuntura, tendo em vista a existência de uma fronteira material e simbólica que divide a cidade? Haja vista, em outras palavras, a afirmação de que há uma fronteira de sentidos que segrega o Rio de Janeiro entre cidade e comunidades, segrega também os moradores entre aqueles que estão dentro ou fora da cidade, cuja imagem de favela é a de um problema social, dita fratura urbana, "como território de violência e da pobreza, da ilegalidade frente à cidade 'legal'" conforme Valladares (2005, p. 20; grifos da autora). Sendo que esse imaginário de favela contribui para sua constante criminalização, para a reiteração do imaginário de cidade partida.

Já no que se refere ao morador de favelas, o que circula em distintos discursos é a reverberação de um efeito de metonimização (COSTA, 2014) do qual deriva a relação entre favela e favelado, ou seja, espaço e sujeito. Todos os sentidos que constituíram ao longo da história a imagem de favela recaem sobre favelado. O lugar de inscrição do morador, conforme Medeiros (2011, p. 212), configura-se assim como um lugar "foradentro: fora dos direitos, mas neles incluído pelas penalizações", isto é, seu lugar de inscrição é marginalizado.

Em resumo, as condições de produção do discurso de pacificação no Rio de Janeiro são constituídas pelo espaço político-simbólico da favela, pela disposição do espaço na relação com o sujeito (morador, policial, traficante), pela polícia e a violência policial, pelas políticas de segurança pública pautadas no extermínio e, sobretudo, pelo modo como o Estado intervém nessas relações, que são relações hierarquizadas, socialmente determinadas, de força e poder (COSTA, 2014).

É possível observar o funcionamento do discurso da UPP em seu site ${ }^{8}$. Destaco algumas das discursividades ${ }^{9}$ que constituem seu discurso:

A UPP mantém a paz nos morros do Rio de Janeiro desde 2008;

A ação da UPP permite a entrada do Estado nas favelas;

Beneficia pessoas;

Faz os moradores se sentirem seguros em relação à violência nas favelas;

Faz o país sentir orgulho do que a polícia do seu país é capaz de fazer;

As forças de segurança do país são capazes de deter o crime;

\footnotetext{
${ }^{8}$ http://www.upprj.com/index.php/as_upps. Acesso em março de 2015.

${ }^{9}$ Referidas à pesquisa de Marcos Antonio Rogel Junior, meu orientando de Iniciação Científica, bolsista da Fapemig.
} 


\section{A conquista é a retomada de vários territórios;}

Promove segurança, cidadania e inclusão social.

O que se explicita a partir dessas discursividades é um jogo estabelecido entre o fora e o dentro da favela, no qual o Estado entra com a polícia; no qual segurança, cidadania e inclusão social estão nessa mesma via em meio a uma série de indeterminações acerca de quem são os moradores que se sentem seguros: do Rio ou das favelas? Quem são as pessoas beneficiadas? O que significa retomar território?

O projeto de pacificação descrito no site afirma que o objetivo da UPP é assegurar a "retomada permanente de comunidades dominadas pelo tráfico, assim como a garantia da proximidade do Estado com a população" e, também, que a UPP considera que a "pacificação ainda tem um papel fundamental no desenvolvimento social e econômico das comunidades, pois potencializa a entrada de serviços públicos, infraestrutura, projetos sociais, esportivos e culturais, investimentos privados e oportunidades". Retomada de território e aproximação do Estado é o que almeja a UPP, produz-se, nesses dizeres, um estranhamento, pois significar pacificação na relação com território e aproximação do Estado é de certa maneira apontar para favela como um espaço não contido no nacional (aquele que está fora, a ser conquistado) e para necessidade de mediação/de mediadores (aí a polícia, força repressiva) entre Estado e favela. Quem é o inimigo aqui?

Textualiza-se, nos dois trechos acima, o discurso que associa a pacificação ao desenvolvimento social e econômico das comunidades, atribuindo à permanência da UPP nas favelas, essa possibilidade. A pacificação sendo significada mais uma vez em relação ao desenvolvimento econômico acrescido do social, ao controle social e, em face de um inimigo, fazendo vir à tona outro nó de sentidos de proteção, inimigo, segurança e insegurança; presença e ausência do Estado etc., que justamente se indistinguem na relação com pacificação.

O discurso da pacificação é assim marcado pelo movimento de indistinção, pois como define Orlandi (1996), a indistinção é a "presença de dois no espaço de um: seja do sentido, seja do sujeito, seja da língua". Esse movimento de indistinção torna-se mais explícito ao passo dá visibilidade para as fronteiras entre as formações discursivas quando se observa o discurso dos moradores de favelas sobre a pacificação, lembrando que os sentidos derivam de e são determinados por formações discursivas.

\section{Dois mundos em um só}

Nessa perspectiva, trago para essa reflexão, recortes extraídos do discurso de moradores do Complexo do Alemão durante uma manifestação contra a violência policial, realizada em abril de 2015, logo após a morte de Eduardo, de 10 anos, que foi baleado por um policial da UPP na porta de sua casa.

Sobre a morte de Eduardo, em entrevista ao Jornal Hoje, a polícia afirma que Eduardo foi atingido em meio a um confronto com traficantes. Mas, de acordo com a mãe do menino: "não estava havendo tiroteio nenhum. Ele disse que meu filho tava com uma pistola e o que tava na mão dele era o celular e ele atirou no meu filho de perto, de uma 
distância de menos de 10 metros. Ele viu que era uma criança. A arma que ele disse é esse celular aqui" 10 .

Sobre os policiais da UPP, um morador denuncia para a Revista Veja que: "eles fazem o que querem no morro, não estão lá para proteger ninguém"11.

Os dizeres dos dois moradores explicitam que a violência e arbitrariedade policial são também exercidas pela UPP, que essa unidade específica não protege e faz o que quer no morro.

Durante a manifestação de abril, os moradores, dentre eles muitas crianças e adolescentes, foram às ruas carregando cartazes que enunciam, conforme as fotografias ${ }^{12}$ abaixo: "um filho perde a mãe e mãe perde um filho... Assim que estamos sobrevivendo no CPX \#paz \#luto; "-bala + amor"; "a favela paz"; "merecemos viver s/medo de morrer"; "Fora UPP".
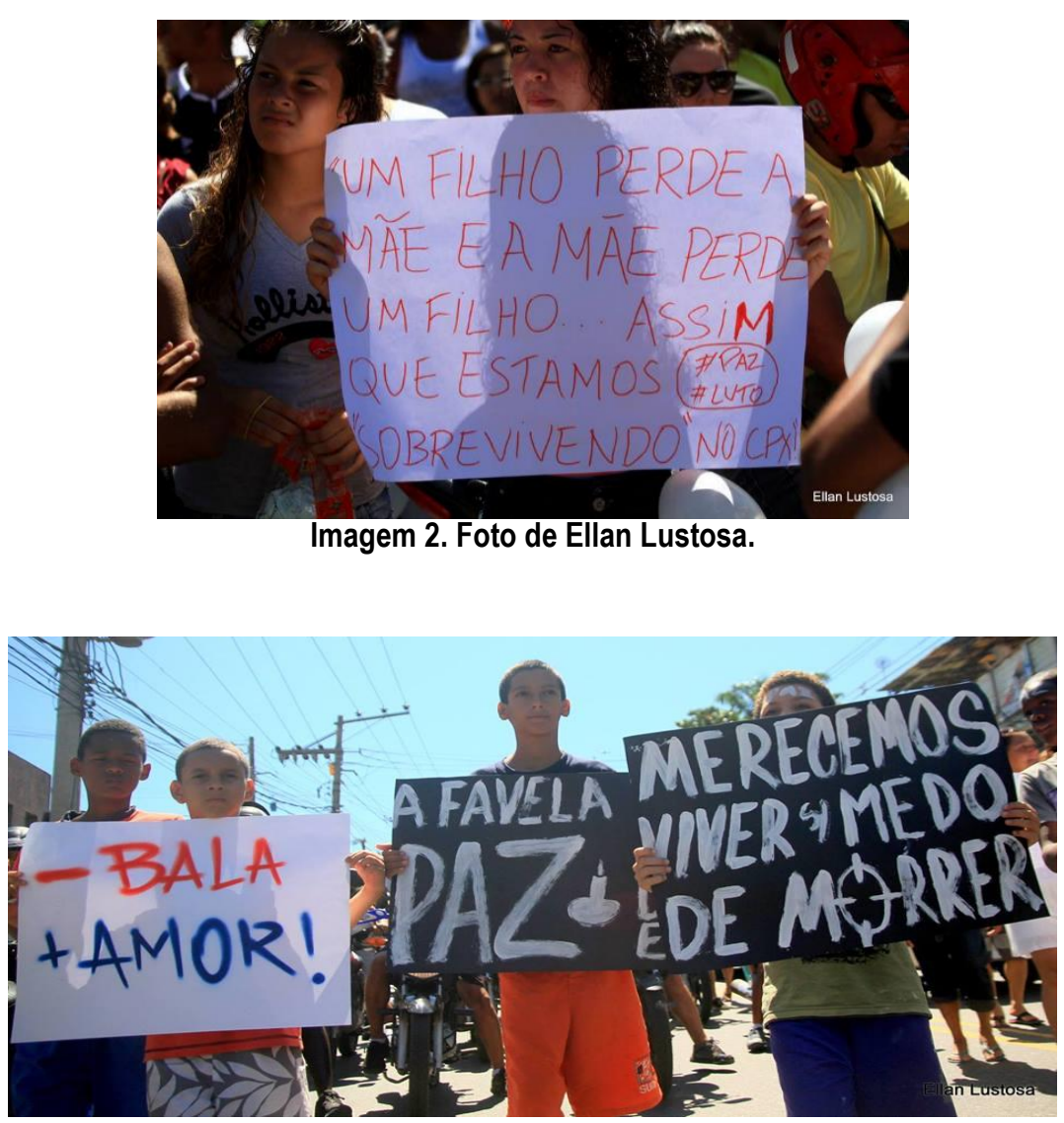

Imagem 3. Foto de Ellan Lustosa.

\footnotetext{
10 Moradores fazem caminhada para pedir paz no Complexo do Alemão. Jornal Hoje (04-04-2015). Disponível em <http://g1.globo.com/jornal-hoje/noticia/2015/04/moradores-fazem-caminhada-para-pedirpaz-no-complexo-do-alemao.html>; acesso em maio de 2015.

${ }^{11}$ A armadilha montada para os moradores do Pavão-Pavãozinho: protesto pede "fim da UPP". Revista Veja. Disponível em <http://veja.abril.com.br/noticia/brasil/a-armadilha-montada-para-os-moradores-dopavao-pavaozinho-protesto-pede-fim-da-upp>; acesso em maio de 2015.

12 Fotos de Ellan Lustosa/A Nova Democracia. Rio de Janeiro, 4 de abril de 2015. Disponíveis em $<$ https://www.facebook.com/jornalanovademocracia/photos/pcb.812613408808329/812612725475064/?t ype $=3 \&$ theater $>$; acesso em maio de 2015 .
} 


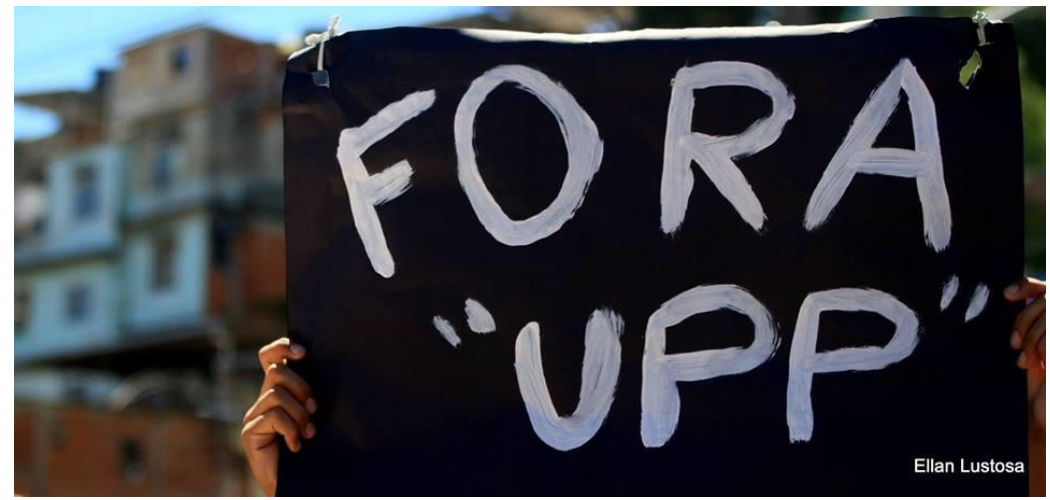

Imagem 4: Foto de Ellan Lustosa

O confronto dessas discursividades com as discursividades que constituem o discurso da UPP explicita uma fronteira de sentidos. De um lado, os moradores pedem paz, significando-a em oposição à bala, a luto, a medo, à morte, à perda de mães e filhos, à presença da UPP, à guerra, à violência. De outro lado, no discurso da polícia, do Estado, a pacificação é definida na relação com guerra, inimigo, violência, segurança.

Paz e pacificação não mantêm uma relação sinonímica. Os sentidos de pacificação e de paz parecem se inscrever em formações discursivas diferentes, mas fronteiriças pelo o modo como certos sentidos deslizam de uma para a outra. Eles vacilam.

Pêcheux ao se referir ao entrelaçamento desigual da formação discursiva com um exterior, indica a existência de fronteiras entre formações discursivas dizendo da necessidade de compreensão das "zonas atravessadas por toda uma série de efeitos discursivos, tematizados como efeitos de ambiguidade ideológica, de divisão, de resposta pronta e de réplica 'estratégia"' (PÊCHEUX, [1983] 1997, p. 314). O autor acentua, dessa forma, uma "vacilação discursiva que afeta dentro de uma FD as sequências situadas em suas fronteiras, até o ponto em que se torna impossível determinar por qual FD elas são engendradas" (idem, ibidem, p. 314).

No que se refere à pacificação, como consequência da impossibilidade de medir as fronteiras de um dizer e outro, de uma formação discursiva e outra, o ganho está no reconhecimento de que a evidência de seu sentido, conforme Orlandi (1999, p. 45), é um efeito ideológico. Como tal, o discurso da pacificação é constituído pelos sentidos tanto guerra quanto o de paz, ou seja, é marcado pela contradição, pois constitui-se de "dois mundos em um só" (PÊCHEUX, 1980, p. 195).

\section{Algumas considerações}

Trabalhar com a análise de discursos é trabalhar sempre com des-limites da linguagem e da significação, lidando com a fronteira entre o dito, o não-dito, o já-dito, o dizível e o a se dizer; entre o excesso e a falta; entre o que cabe ou transborda em uma ou outra formação discursiva; entre o sentido que repousa em uma ou outra palavra, que remete a uma ou outra região da memória discursiva. 
São muitas as fronteiras mais ou menos visíveis com as quais se lida quando se analisa o funcionamento discursivo e suas discursividades, considerando a relação entre a língua, a história e o social. Isso porque a Análise de Discurso, como ressalta Orlandi, leva "em conta o homem na sua história, considera os processos e as condições de produção da linguagem, pela análise da relação estabelecida pela língua com sujeitos que a falam e as situações em que se produz o dizer" (1999, p. 16). Sendo assim, é preciso considerar essas fronteiras em pelo menos duas instâncias: 1. a fronteira com a qual se lida teoricamente, tendo em vista o trabalho constante com os des-limites da linguagem; 2. a fronteira que marca as relações sociais que, como explica Orlandi (2001), são relações de sentido. Fronteiras do discurso em face da fronteira dos espaços e dos sujeitos em sociedade, cujas relações produzem sentidos no/pelo discurso. Fronteira que é simbólicapolítica-ideológica, que constitui a produção de efeitos de sentido, tomada enquanto espaço de significação.

Em referência à pacificação, num primeiro momento, o jogo constante entre descobrir, conquistar e dar conhecer, no processo histórico de colonização, constrói a imagem do índio como inimigo, de seu entorno, e a faz circular. No momento atual, uma política pública de retomada de território, de "conquista revestida", faz emergir novamente a imagem de inimigo. Essa imagem, certamente, produz efeitos de sentido, impulsiona e sustenta formas de regulação da sociedade. É preciso desnaturalizá-la para que as políticas de Estado, por meio das forças policiais, que historicamente se constituem como repressivas, não cometam mais atrocidades em nome de pacificação.

\section{Referências bibliográficas}

COSTA, G.C. Sentidos de milícia: entre a lei e o crime. Campinas, SP: Editora da Unicamp, 2014.

MEDEIROS, V. "Posso me identificar?": mídia, violência e movimentos sociais. Em: ZANDWAIS, A.; ROMÃ̃, L.M.S. (Orgs.). Leituras do político. Porto Alegre: Editora da Universidade Federal do Rio Grande do Sul, 2011. pp. 201-219.

NOVARO, M.; PALERMO, V. A ditadura militar argentina 1976-1983: do golpe de estado à restauração democrática. São Paulo: Editora da USP, 2007.

ORLANDI, E.P. Discurso e texto: formulação e circulação dos sentidos. Campinas, SP: Pontes, 2001.

Análise de Discurso: princípios e procedimentos. Campinas, SP: Pontes, 1999.

Vozes, 1996.

Terra à vista. Discurso do confronto: Velho e novo mundo. Campinas, SP:

Editora da Unicamp, 1990. 
PACHECO DE OLIVEIRA, J. Pacificação e tutela militar na gestão de populações e territórios. MANA, vol. 20, n. 1, Rio de Janeiro, abril de 2014.

PÊCHEUX, M. [1977]. As massas populares são um objeto inanimado? Em: Análise de discurso: Michel Pêcheux. Textos selecionados por Eni Puccinelli Orlandi. Campinas, Pontes, 2011.

Análise automática do discurso. Trad. Bras. Em: GADET, F.; HAK, T. (Orgs.). Por uma análise automática do discurso: uma introdução à obra de Michel Pêcheux. $3^{\mathrm{a}}$ ed. Campinas: Unicamp, 1997.

[1975] Semântica e Discurso: uma crítica à afirmação do óbvio. Trad. Bras. Campinas-SP: Editora da UNICAMP, 1988.

Remontémonos de Foucault a Spinoza. Em: TOLEDO, M.M. (Org). El discurso político. México: Nueva Imagen, 1980.

VALLADARES, L.P. A invenção da favela: do mito de origem à favela.com. Rio de Janeiro, Editora FGV, 2005.

Artigo recebido em: junho de 2016.

Aprovado e revisado em: julho de 2016.

Publicado em: agosto de 2016

\section{Para citar este texto:}

COSTA, Greciely Cristina da. Discursos de pacificação e a divisão de sentidos e sujeitos. Entremeios [Revista de Estudos do Discurso], Seção Temática [Os discursos sobre segurança em meio a políticas e processos de significação], Programa de Pós-graduação em Ciências da Linguagem (PPGCL), Universidade do Vale do Sapucaí, Pouso Alegre (MG), vol. 13, p. 183-196, jul. - dez. 2016.

DOI: http://dx.doi.org/10.20337/ISSN2179-3514revistaENTREMEIOSvol13pagina183a196 